\title{
REFLECTION
}

McGill Journal of Medicine

\section{Not Knowing What to Do: A Narrative Reflection on a Medical Student's First Patient Encounter}

\section{Emmanuel Adams-Gelinas ${ }^{1}$}

${ }^{1}$ McGill University, Montreal, QC, Canada

\section{Correspondence}

Emmanuel Adams-Gelinas

Email:

emmanuel.adams-gelinas@mail.mcgill.ca

Publication Date

March 2, 2021

MJM 2021 (19) 12

https://doi.org/10.26443/mjm.v19i1.843

\section{Journal of Medicine}

www.mjmmed.com

\section{(c) (i) (2)(2)}

This work is licensed under a Creative Commons BY-NC-SA 4.0 International License.

\begin{abstract}
Medicine, though fundamentally a scientific discipline, is the art of transferring experimentally derived knowledge onto the care of patients. The clinician's role is to master precisely that process. Therefore, in addition to acquiring a strong command of the biomedical sciences, integral to the clinician's professional duty is the development of his or her identity as a healer.

This first-person narrative essay explores a clinical encounter between myself, a first-year medical student with very limited clinical experience, and an elderly man whom I found collapsed on the sidewalk. Fumbling in my clinical decision-making, I settle on simply holding the man's hand to reassure him that his ambulance is on its way. Later, after reflecting on the event and obsessing over my blunders and hesitations, I finally recognize that the simple act of holding his hand was essential to my role as a future physician and healer, rather than implying clinical inadequacy.
\end{abstract}

\section{KEYWORDS}

Narrative, Physicianship, Medical Humanities
I was walking over to my father's apartment to pick up his old iPhone; mine had decided to die its programmed death that day. For medical students, Friday evenings offer both the blessing of freedom and the curse of exhaustion from a week spent studying to circuit-failure. For this reason, I decided to walk-and not take the metro-to my father's apartment, with nothing but my thoughts supplied by the cold air, a smooth jazz album to calm the neurons, and the faces of strangers with whom I could lock eyes even if only for a transient moment, each of them a sacred snapshot of humanity amidst the masked figures of quarantine.

As medical students, we are constantly reminded by experienced clinicians that a healthy mental life should not be sacrificed for the sake of tireless, self-destructive perfectionism. This advice comes as a relief, given that popular culture tends to depict medical superiors as authoritarian drill sergeants with nothing but hard lessons to teach us by means of pain, sweat and psychological abuse. But how quickly I was, in my first few months 
of medical school, already betraying their advice. Relaxation already seemed like a waste of time, especially when exams were around the corner. "And on top of that," I would always repeat to myself robotically, "I'm going to have to save lives one day. Damn it, I shouldn't excuse any moment spent wavering from that goal."

In time I learned that tireless studying and annihilating every facet of my private life was not conducive to well-being, nor to a better understanding of the material. So that's why I decided, that Friday evening, to walk over to my father's apartment instead of taking the metro. It feels almost serendipitous now, thinking back, that the first time that I would provide urgent medical care was also the first time I would decide, with much deliberation, to distance myself from the study of medicine for one short evening.

It was dark and the streetlights shone puddles of warm light like flattened blood oranges across the sidewalk. From a few meters away, all I could see was the silhouette of backward stumbling legs-drunk, seeminglyand a couple of teenagers sharing Tik Tok clips while waiting for the bus. However, when I approached the bus stop, I realized that the silhouette belonged to an elderly man who had lost function in both legs, suddenly crumbling down against the brick wall behind him and attempting to clutch an invisible buoy in the air.

To my surprise, my response was automatic. I removed the crumpled mask from my back-pocket, strung it around my ears, and directed the teenage boys standing by the curb to "Call 9-1-1 right now and tell them exactly what I say."

Recognizing the urgency in my tone, the taller, thinner teenager did not hesitate to call the ambulance, while the other came over and admitted, in a tremulous voice that was part guilt and part innocence, that he had noticed the man was having difficulty standing but had mistakenly assumed he was drunk. I reassured him that I had thought the same thing.

I leaned over and felt the elderly man's pulse in his wrist. I could hardly differentiate it from my own heart, which was beating hard and fast through the distal end of my thumb. Of course, I thought to myself, foolishly, they told you a hundred times in that CPR course: do not use your thumb.

"Is he conscious? Is he conscious?" asked the teenager whom I had instructed to call 9-1-1.

"Yes," I said, hesitating, as I felt the man's carotid artery with my index and middle finger. "Yes, yes, yes," I then repeated when I had confidently appreciated the man's pulse, and proceeded to confirm that he was, in fact, breathing.

"He's conscious," the teenager screamed over the phone. "But where are you? Why are you asking questions? Send the ambulance!"

"Just relax," I said to the boy, without heeding to my own advice, "they'll be here soon."

The old man started falling to his side. I held him in my arms and heaved his body back to a seated position. I looked into his eyes; he could barely open them, and his tongue was slipping out of the right side of his mouth.

"Do you speak English?" I asked him.

He responded by slurring something that sounded vaguely Italian.

\section{"Français?"}

This elicited a similar response, except with an accent of intense, visceral panic.

Emptiness swallowed the world. A clear, elucidating emptiness: here I was, a useless student. I had already exhausted everything I knew to do in this situation, which wasn't much at all. I was staring at a man's suffering face, the folds in his cheeks traveling the thin parameters of consciousness, with nothing to offer him. All I knew, in that moment, was that he was conscious and alive-at least for that moment-and that he was suffering a great deal. But then I felt a squeezing pain in my forearm that I will never forget-a pain that will be imprinted like a wax seal in my memory: the man's right hand, grasping me, with a force only exerted when the pull of death is tugging at you hard.

His eyes opened.

"Sir," he pleaded, clearly and audibly this time, "please help me."

"The ambulance is coming," I replied, as I moved his hand toward my own and he squeezed it with even greater compression. "They will be here soon," I stressed. 
I held his hand like this for at least five minutes until the paramedics arrived. Clearing my way for them, I was grateful to surrender my position to the paramedics who, unlike me, were experts in managing such situations. They performed all sorts of tests and quickly concluded that the man had most likely suffered an acute neurological episode, which, on reconsideration, was quite obvious (of course, in retrospect, everything always seems so obvious).

A police officer interrogated the two teen boys and me and then asked us to leave with a procedural smile.

"You can go now."

The officer had seen this a thousand times before and knew the drill, just like the firemen and the paramedics. With experience and application, their theoretical lessons had long ago evolved into intuitive, visceral practice. I went into the metro station, disinfected my hands, and glanced over at the scene through the window before going off to my father's apartment building. I picked up his old iPhone from the mailbox (pandemic precautions) and turned around to head back home again.

I followed the same route in reverse, replaying the scene in my mind in endless loops, with each playthrough more detailed than the last. The details tortured me, every one of them like a sharp pin-needle pricking my brain, evoking all of the wrong decisions I might have made and, worse, all of the potential disastrous consequences of those decisions.

Upon passing the bus stop, a kind of mundanity set in. What was, roughly 30 minutes prior, a space of chaotic disturbance, alarmed by the constant flickering of ambulance and police lights and energized by the coordination of emergency care workers, had been replaced with its usual late evening scenery. Employees were waiting in line for the bus, open metro doors vacuumed the air, and a loud choir of honking dominated the intersections. All of my concerns regarding my actions, decisions, and indecisions already seemed irrelevant in the renewed atmosphere of regularity; they were things of the past, errors to be forgotten rather than scrutinized. The man whose hand I held was likely in an emergency room by now, hopefully still breathing, and surrounded by health- care workers.

Ironically, the day I decided to distance myself from the study of medicine was the same day I was forced to practice it. I took a man's pulse, held his hand, and told him that the paramedics were arriving. Perhaps my contributions to that man's health were minimal, but the incident reinforced the notion that medical theory will never provide a complete picture of medical care-the gestalt will only come to fruition once the floating abstractions of our knowledge are forced to face a human person with a real pulse, real problems, and real fears.

It was out of desperation that I ended up holding that man's hand to reassure him, just as it was out of desperation that he pleaded for my help. One day, in a not-so-distant future, I will have learned to apply clinical medicine, and I hope never to end up holding a suffering patient's hand out of desperation again. Yet, at the same time, physicianship demands of us that we do not treat basic acts of humanism in medicine as surrendered acts of desperation, but as integral to our very profession. Unfortunately, I can already foreshadow that the relentless drive toward improving my clinical abilities might one day overhaul my drive for empathy, just as I became obsessive with every negative detail of my first patient-encounter without counterbalancing them with successes. I treated myself, that Friday evening, like a broken physiological mechanism whose satisfactory function emerges only at near-perfect operation, rather than like a person.

Nobel prize-winning physician Dr Bernard Lown, referring to "medicine's profound crisis", wrote that "doctors no longer minister to a distinctive person but concern themselves with fragmented, malfunctioning biologic parts. The distressed human being is frequently absent from that transaction". (1) I often worry that I will eventually find my professional self to be more robotic than human and in turn treat patients like alien systems. In this sense, I should not assume that empathy will always come to me naturally; we ought to think of empathy as an ongoing clinical requirement, a kind of intuition with its own set of practical applications rather than a noble, but ultimately stagnant, principle.

So, as it turns out, I owe a lot to the man whose hand 
I held on the side of the road-he allowed me to put principle into practice.

\section{REFERENCES}

1. Lown B. The Lost Art of Healing. New York: Ballantine Books; 1999. 